\title{
Epstein-Barr virus-based vector improves the tumor cell killing effect of pituitary tumor in HVJ-liposome-mediated transcriptional targeting suicide gene therapy
}

\author{
TSUYOSHI IZUMO ${ }^{1}$, AKIRA OHTSURU $^{2,3}$, YOSHIHARU TOKUNAGA ${ }^{4}$, HIROYUKI NAMBA $^{2}$, \\ YASUFUMI KANEDA ${ }^{5}$, IZUMI NAGATA ${ }^{1}$ and SHUNICHI YAMASHITA ${ }^{2,3}$
}

\begin{abstract}
Departments of ${ }^{1}$ Neurosurgery, and ${ }^{2}$ Molecular Medicine, Nagasaki University, Graduate School of Biomedical Science,
${ }^{3}$ Takashi Nagai Memorial International Hibakusha Medical Center, Nagasaki University Hospital, 1-7-1 Sakamoto,

Nagasaki 852-8501; ${ }^{4}$ Nagasaki Prefecture Shimabara Hospital, 7895 Shimokawajiri-chou, Shimabara-City,

Nagasaki 855-0861; ${ }^{5}$ Division of Gene Therapy Science, Osaka University, Graduate School of Medicine,

2-2 Yamada-oka, Suita-City, Osaka 565-0871, Japan
\end{abstract}

Received December 18, 2006; Accepted February 9, 2007

\begin{abstract}
Although tissue-specific promoters offer a promising approach to the targeting of gene therapy, the activity of such promoters is generally low, which is thus a major limitation, especially when using non-viral vectors. To establish effective transcriptional targeting gene therapy for growth hormone $(\mathrm{GH})$ producing pituitary tumors, an Epstein-Barr virus (EBV) based vector system expressing herpes simplex virus type 1 thymidine kinase (HSV1-TK) driven by a rat GH promoter (pEBGTK) was developed. This harbors an EBV nuclear antigen-1 (EBNA-1) gene with an origin of the latent viral DNA replication (OriP) gene of EBV. We constructed an EBVbased luciferase plasmid (pEBGL) as a reporter plasmid. We also generated pGTK and pGL, which are non-EBV counterparts. Metastatic GH3 (mGH3) cells were used in this study. The transfection of pEBGL to $\mathrm{mGH} 3$ resulted in approximately a 39 times greater luciferase activity than pGL in vitro. Its expression was also prolonged $144 \mathrm{~h}$ after transfection. According to the results of pEBGL gene transfer in in vivo experiments, the luciferase activity was only observed in the tumors, but not detected in other normal tissues. The luciferase activities in tumor tissues were found until day 25 post transfection. During in vitro gene therapy, the transfection by pEBGTK using hemmaglutinating virus of Japan (HVJ) liposome enhances the susceptibility of $\mathrm{mGH} 3$ to gancyclovir (GCV) 110 times more than that by pGTK. The in vivo antitumor effects of pEBGTK on $\mathrm{mGH} 3$-tumor-bearing nude mice were evaluated. The intratumoral injection of HVJ anionic
\end{abstract}

Correspondence to: Dr Akira Ohtsuru, Takashi Nagai Memorial International Hibakusha Medical Center, Nagasaki University Hospital, 1-7-1 Sakamoto, Nagasaki 852-8501, Japan

E-mail: ohtsuru@nagasaki-u.ac.jp

Key words: Epstein-Barr virus, gene therapy, pituitary tumor lipososme-enveloped pEBGTK followed by the intra-peritoneal injection of GCV demonstrated a significant growth inhibition against tumors without toxicity, while the tumors treated by other treatment modalities grew progressively. These results demonstrated that the EBV-based vector system can therefore contribute to the improvement of the anti-tumor effects for the HVJ-liposome-mediated transcriptional targeting suicide gene therapy, suggesting that this paradigm may thus be a potentially effective approach for the treatment of uncontrollable pituitary tumors.

\section{Introduction}

Pituitary adenomas represent $15 \%$ of all primary intracranial neoplasms (1), and they are often considered to be histopathologically benign tumors. Despite recent therapeutic advances in such treatment modalities as transsphenoidal microsurgery, receptor-mediated pharmacotherapy, and radiation therapy, some pituitary adenomas remain uncontrollable (2). Pituitary carcinomas are rare, but life-threatening tumors, which tend to originate in the anterior pituitary gland and thereafter undergo cerebrospinal fluid dissemination or systemic metastasis (3-7). They are refractory to current available treatments (6-8). As a result, there is a need to develop new treatment strategies for such uncontrolled pituitary tumors.

Gene therapy appears to be a potentially effective strategy for the treatment of pituitary tumors $(9,10)$. A variety of studies have been performed using viral vectors as gene therapy for pituitary adenomas both in vitro and in vivo. Preclinical experiments of cytotoxic or suicide gene therapy for pituitary adenoma model, using cell-specific promoters and adenoviral vectors, have been conducted and the results have shown remarkable cytopathic and tumor suppression effects (11-18). Pituitary adenomas are usually localized tumors, so the direct injection of vectors is a realistic and potentially useful modality. The stereotactic injection of adenoviral vectors has been successfully and safely performed in rat pituitary adenoma models $(19,20)$, and the transsphenoidal direct injection of 
vectors might thus be used for residual adenomas in humans (21). However, the viral vector application is restricted by various shortcomings, including the induction of immune responses, endogenous viral recombination, and oncogenic effects (22-27). Significant hypophysitis has been reported after the adenovirus-mediated gene transfer in pituitary gene therapy (28). No matter how transcriptional targeting is achieved by tissue-specific promoters, these adverse reactions by the viral vector itself are critical, for both benign and slow growing pituitary adenomas $(29,30)$.

Non-viral vectors have attracted a great amount of attention in recent years because they are expected to allow us to eventually achieve gene therapy without serious side-effects (31). However, the most critical issue of gene transfer using non-viral vectors is the low expression abilities of the desired gene $(32,33)$. This phenomenon results in a marginal therapeutic effect in experimental cancer gene therapy, thus resulting in a major limitation of its application to clinical trials. To obtain an adequate effect of tissue type specific gene therapy, both a stronger and longer expression ability of the vector system is therefore thought to be crucial.

To overcome this problem, an Epstein-Barr virus based vector system was used in conjunction with a rat growth hormone promoter, as the cell-targeting promoter. This vector harbors the cis-acting oriP (the latent viral DNA replication origin) and the trans-acting EBV nuclear antigen-1 (EBNA-1) sequences of EBV genome, which are required for EBV latent infection $(34,35)$. This is characterized by the autonomous replication and nuclear retention of the EBV genome in the host cells, both of which are one of the mechanisms through which the EBV-based vector activates the transgene expression (36).

This is the first report of pituitary cancer gene therapy which has been strengthened by the combination of a hormone specific promoter and an EBV-based expression vector system, thereby providing us with an important knowledge of the usefulness of tissue-specific cancer gene therapy using nonviral vectors.

\section{Materials and methods}

Cell lines. The rat somatotroph tumor cell line (GH3) and the rat glioma cell line (C6) were obtained from American Type Culture Collection (Manassas, VA). The metastatic GH3 cell line (mGH3) was established from lymph node metastasis that developed 3 months after the subcutaneous implantation of GH3 in Wister-Furth female rats, as we described previously (37). These cells were maintained in Ham's F-10 medium containing $15 \%$ horse-serum, $2.5 \%$ fetal bovine serum and $0.5 \%$ penicillin-streptomycin culture conditions, and they were incubated at $37^{\circ} \mathrm{C}$ in a humidified atmosphere exposed to $5 \% \mathrm{CO}_{2}-95 \%$ air gas mixture. All cell culture reagents were purchased from either Invitrogen Japan K.K. (Tokyo, Japan) or Sigma-Aldrich Japan Corp. (Tokyo, Japan).

Plasmid vectors. Plasmid pLNCTK (pCTK), which has the herpes simplex virus type 1 thymidine kinase gene (HSV1-TK) driven by human cytomegalovirus (CMV) promoter, was kindly provided from Dr A. Ido, Kyoto University Hospital, Kyoto, Japan. The HSV1-TK gene was excised from pCTK by
HindIII and $\mathrm{XbaI}$ digestion and cloned into the HindIII-XbaI site of pGL3-basic vector (Promega Corp., Madison, WI) instead of luciferase gene generating pGL3-TK. Rat growth hormone promoter $(-320-0, \mathrm{rGHp})$ was inserted into the HindIII site of pGL3-basic vector and pGL3-TK generating pGL and pGTK, respectively. rGHp-luciferase and rGHpHSV-TK cassettes were excised from pGL and pGTK by Not $\mathrm{I} / \mathrm{XbaI}$ and cloned into $\mathrm{pEBC}$, which contains a truncated EBNA-1 and OriP sequence as previously described (38), thus generating pEBGL and pEBGTK, respectively. The vectors are summarized in Fig. 1.

Preparation of HVJ-liposomes. A lipid membrane was generated by drying $10 \mathrm{mg}$ of lipid mixture using a rotary evaporator. A DNA-containing liposome was constructed from the lipid membrane and $200 \mu 1$ of balanced salt solution (BSS) containing $200 \mu \mathrm{g}$ of DNA with vortexing method. The liposome was fused with the ultraviolet-inactivatedhemagglutinating virus of Japan (HVJ) followed by purification by sucrose density gradient ultracentrifugation to form HVJliposomes (39). The final liposome suspensions were prepared as a BSS mixture, each volume was 1000 and $3000 \mu 1$ for in vitro and in vivo use, respectively.

Optimized HVJ-cationic liposomes (HVJ-opDC liposomes) were used for the in vitro experiments. The lipid composition was as follows: egg phosphatidylcholine (ePC):dioleoylphosphatidylethanolamine (DOPE):egg sphingomylin (eSph): cholesterol (Chol):3ß-[N-(N',N"'-dimethyl-aminoethan) carbanoyl] cholesterol $(\mathrm{DC}-\mathrm{Chol})=5: 5: 5: 12: 3$ in a molar ratio (40). For in vivo experiments, we selected an HVJ-artificial viral envelope (AVE) anionic liposome, as previously described (41). The lipid composition was as follows; ePC:DOPE:eSph: bovine brain phosphatidylserine (bPS): $\mathrm{Chol}=16.7: 16.7: 16.7$ : 10:5 in a molar ratio.

In vitro luciferase assay. The cells were passaged onto 24-well plates at a density of $2 \times 10^{3}$ cells per well $24 \mathrm{~h}$ before transfection. To correct for transfection efficiencies, one microgram per well of pGL or pEBGL was transferred with $0.02 \mu \mathrm{g}$ per well of positive control plasmid pRLCMV, harboring a renilla luciferase gene driven by human cytomegalovirus promoter, to the cells using the HVJ-opDC cationic liposome method. After $24 \mathrm{~h}$, the liposome containing media were changed to fresh media. Harvesting was performed every $24 \mathrm{~h}$ in passive lysis buffer (Promega Corp.) from 24 to $144 \mathrm{~h}$ after the transfection. Total cell lysate of $20 \mu \mathrm{l}$ was prepared, and luciferase activity was measured using a dual luciferase reporter gene assay system (Promega Corp.) with a luminometer. At each time point, four samples from 4 wells were used for each assay. We repeated the experiments at least three times.

In vitro gene therapy. The cells ( $\mathrm{mGH} 3$ or $\mathrm{C} 6)$ at a density of $1 \times 10^{3}$ cells per well were plated onto 24 -well plates $48 \mathrm{~h}$ before transfection (day -2). pGTK or pCTK or pEBGTK were transferred into cells, using the HVJ-opDC cationic liposome method (day 0). Two hundred micrograms of each plasmid were mixed with $10 \mathrm{mg}$ of lipids. One microgram of plasmid DNA enveloped by HVJ-liposome was added to each well. After $24 \mathrm{~h}$, liposome containing medium was changed 

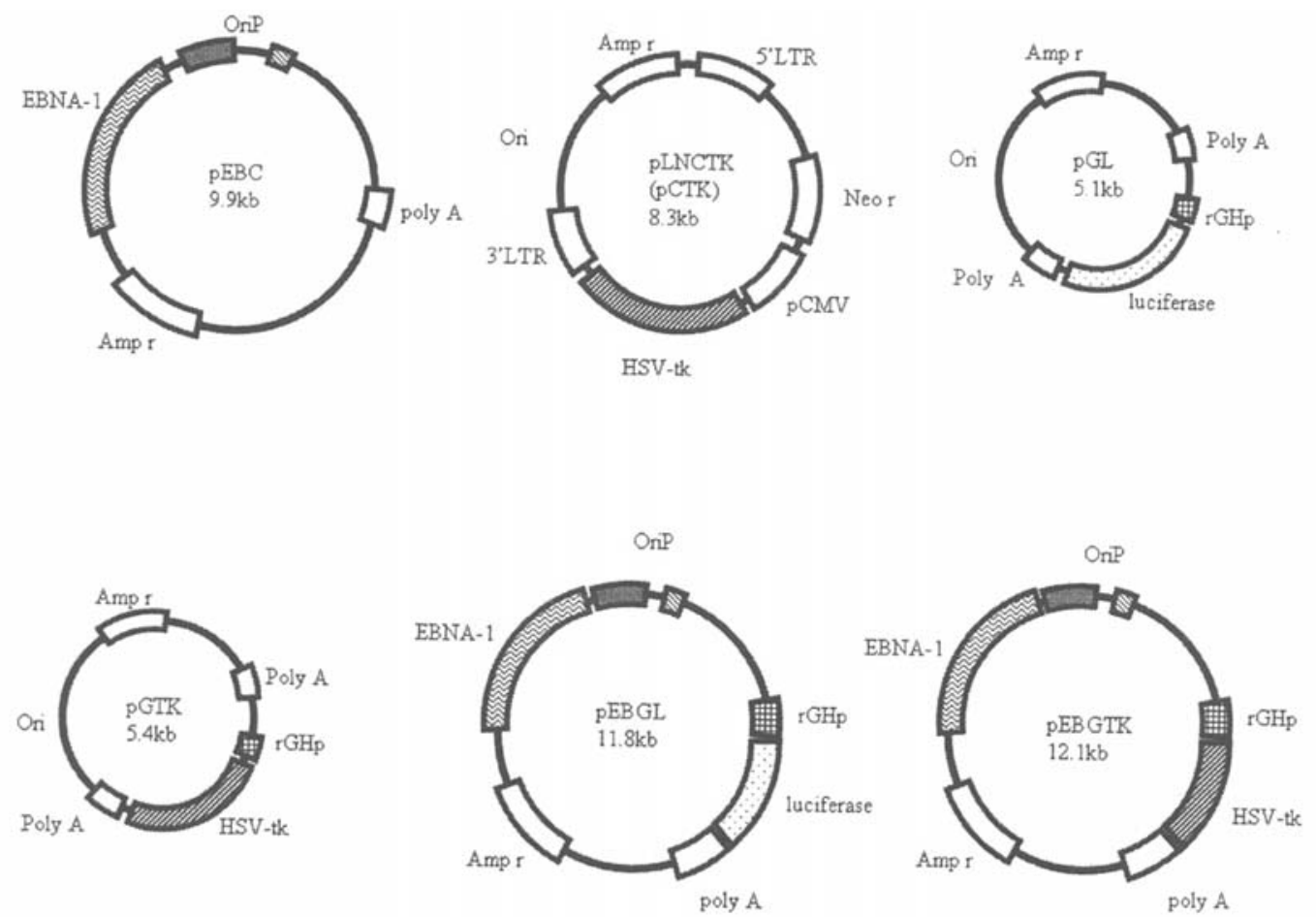

Figure 1. A schematic representation of the plasmids used in this experiment. pCMV, human cytomegalovirus promoter; rGHp, rat growth hormone promoter; EBNA-1, Epstein-Barr virus (EBV) nuclear antigen-1; oriP, EBV latent origin of replication; HSV-tk, herpes simplex type-1 thymidine kinase.

to fresh medium. To test GCV sensitivity, the drug was added to the medium at a final concentration of $0-1000 \mu \mathrm{M}$ daily from day 1 to day 7 . On day 8 , viable cells were counted by means of a trypan blue exclusion method. The median inhibitory concentration $\left(\mathrm{IC}_{50}\right)$, which represents a $50 \%$ growth inhibition relative to the control, was calculated using curving-fitting parameters.

These in vitro gene therapies were carried out in four combinations as follows: GCV group, cells were treated only by GCV; pGTK group, cells were transfected with pGTK followed by GCV treatment; pCTK group, cells were treated by pCTK and GCV; pEBGTK group, cells were treated by pEBGTK and GCV, for each cell line.

Animal experiments. All experimental animals had free access to food and water, a 12-h light, 12-h dark cycle, and constant housing temperature and humidity. They were handled in a humane fashion according to the Nagasaki University Laboratory Animal Care and Use Committee Guidelines. Seven- to 8-week old female athymic mice (BALB/c AnNCrj- $n u$, Charles River Japan Inc., Kanagawa, Japan) or eight- to 10-week old female Wister-Furth rats (Nagasaki University Laboratory Animal Center, Nagasaki, Japan) were used in this study.

In vivo luciferase assay. For the in vivo luciferase assay $200 \mu \mathrm{g}$ of plasmid was mixed with $10 \mathrm{mg}$ of lipids to prepare the HVJAVE anionic liposomes as described previously. To correct for transfection efficiencies, $196 \mu \mathrm{g}$ of pGL or pEBGL were co-transferred with $4 \mu \mathrm{g}$ of positive control plasmid pRLCMV in each experiment. mGH3 cells $\left(1 \times 10^{6}\right)$ were inoculated subcutaneously into the flank area of Wister-Furth rats. Three weeks after the injection of the cells, tumors 5-10 $\mathrm{mm}$ in maximum diameter developed, $200 \mu 1$ of the HVJ-liposome suspension was injected directly into the tumor for three consecutive days. The rats were sacrificed every three days from day 4 to day 25 , and the total homogenate lysates of tumors or various normal tissues/organs were prepared using passive lysis buffer. Luciferase activities of total homogenates were measured as described above.

In vivo gene therapy. Approximately 2 weeks after the injection of $1 \times 10^{6} \mathrm{mGH} 3$ cells subcutaneously into the flank area of nude mice, when the tumor size reached $5 \mathrm{~mm}$ in maximum diameter, the mice were divided into 6 groups as follows: group 1, the tumors were injected with $200 \mu 1$ of pEBGTKenveloping-HVJ-liposome suspension for three consecutive days (day 0-2) followed by the daily intraperitoneal GCV injection of $50 \mathrm{mg} / \mathrm{kg}$ body weight (B.W.) from day 2 to day $14(\mathrm{n}=8)$; group 2, the tumors were injected with $200 \mu \mathrm{l}$ of pGTK-enveloping-HVJ-liposome suspension for three consecutive days (day 0-2) followed by the daily intraperitoneal $\mathrm{GCV}$ injection of $50 \mathrm{mg} / \mathrm{kg} \mathrm{B}$.W. from day 2 to day $14(\mathrm{n}=8)$; group 3 , the tumors were injected with $200 \mu 1$ of pEBGTKenveloping-HVJ-liposome suspension for three consecutive days (day 0-2) without GCV administration ( $n=8)$; group 4, the tumors were injected with $200 \mu 1$ of BSS for three consecutive days (day 0-2) followed by the daily intraperitoneal GCV injection of $50 \mathrm{mg} / \mathrm{kg} \mathrm{B.W}$. from day 2 to day $14(\mathrm{n}=8)$; group 5, the tumors were injected with $200 \mu 1$ of pEBGLenveloping-HVJ-liposome suspension for three consecutive days (day 0-2) followed by the daily intraperitoneal GCV injection of $50 \mathrm{mg} / \mathrm{kg} \mathrm{B}$.W. from day 2 to day $14(\mathrm{n}=8)$; group 6 , the tumors were injected with $200 \mu \mathrm{l}$ of pCTKenveloping-HVJ-liposome suspension for three consecutive days (day 0-2) followed by the daily intraperitoneal GCV 


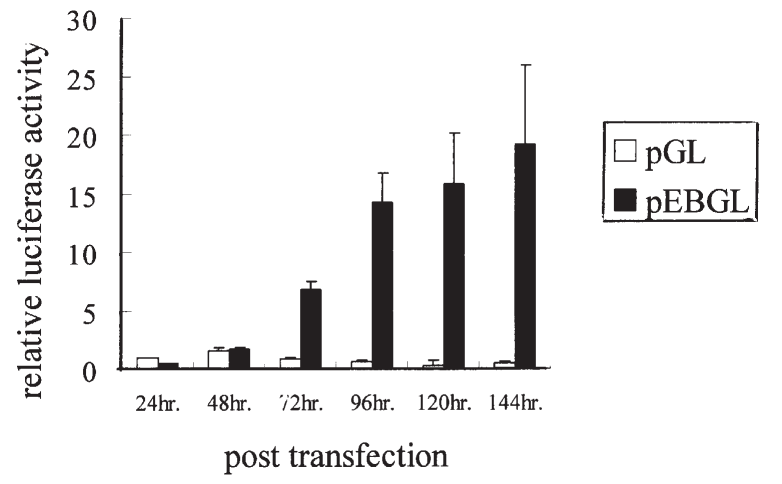

Figure 2. EBV-based vector prolonged and enhanced the transgene expression in vitro. The relative luciferase activity in cultured $\mathrm{mGH} 3$ cells. Cells $\left(2 \times 10^{3}\right)$ were transfected with $1 \mu \mathrm{g}$ of plasmid DNA, using HVJ-opDC cationic liposome method. The ordinate indicates relative light units of firefly luciferase per rinella luciferase activity as measured by a luminometer. The mean value of quadruplicate plates is indicated. The abscissa represents the days after the gene transfer. Using pEBGL, the relative luciferase activity increased daily after transfection. At $144 \mathrm{~h}$ post transfection, the luciferase gene expression of pEBGL was enhanced to a level 39 times higher than that of pGL.

injection of $50 \mathrm{mg} / \mathrm{kg} \mathrm{B.W}$. from day 2 to day $14(\mathrm{n}=8)$. The tumors were measured with a caliper each third day until day 24 or until the tumor size reached $20 \mathrm{~mm}$. The tumor volume was calculated as follows: volume $=\mathrm{a}^{2} \mathrm{x} b / 2\left(\mathrm{~mm}^{3}\right)$, where $\mathrm{a}$ $=$ long diameter and $\mathrm{b}=$ short diameter.

Statistical analysis. For the luciferase assays, cytotoxicity assays and a comparison of tumor volumes, either Student's t-test or the Cochran-cox test was used. A P $\leq 0.05$ was considered to indicate significance. The StatMate III software program for Macintosh (atms, Tokyo Japan) was used for all statistical analyses.

\section{Results}

Enhanced transgene expression using EBV-based expression vector in vitro. We analyzed the transgene expression of plasmid pGL or pEBGL in rat malignant pituitary somatotroph tumor cell lines mGH3 transfected by the HVJ-opDC cationic liposome method. As shown in Fig. 2, when pGL was transfected to $\mathrm{mGH} 3$, the relative luciferase activity increased until $48 \mathrm{~h}$ and then it gradually decreased thereafter. When pEBGL was transfected, the relative luciferase activity increased gradually until $144 \mathrm{~h}$ post transfection. At $144 \mathrm{~h}$ post transfection, the luciferase gene expression of pEBGL was enhanced to 39 times higher than that of pGL, and this activity was 12 times higher than the peak luciferase activity of pGL. No luciferase activity was found in the rat glioblastoma cell line C6 transfected with pEBGL or pGL by HVJ-liposome at $72 \mathrm{~h}$ post transfection (data not shown).

Long-term transgene expression analysis in vivo. HVJ-AVE anionic liposome enveloping plasmid pEBGL and pRLCMV was injected directly to the subcutaneous tumor developing on a flask of Wister-Furth rats. As shown in Fig. 3A, the luciferase activity was assayed from day 4 until day 25 after transfection. The activity remained elevated until day 7 after

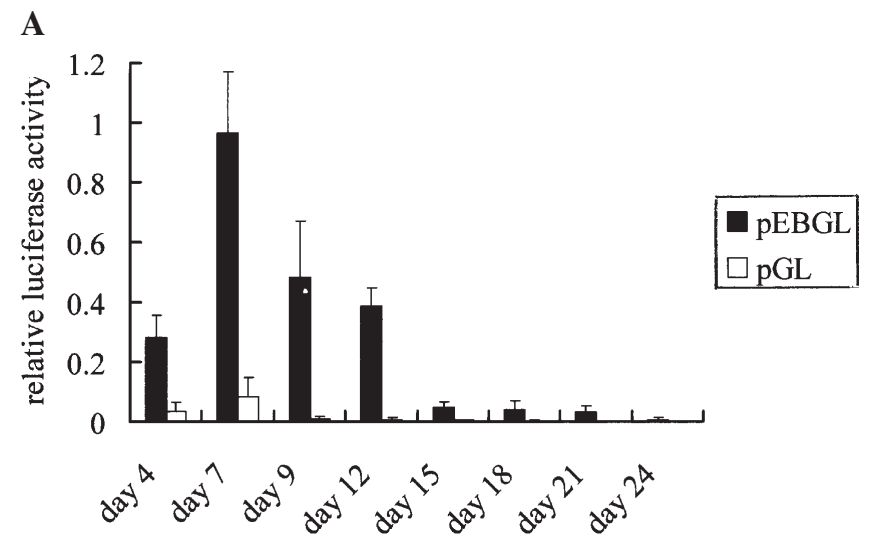

B

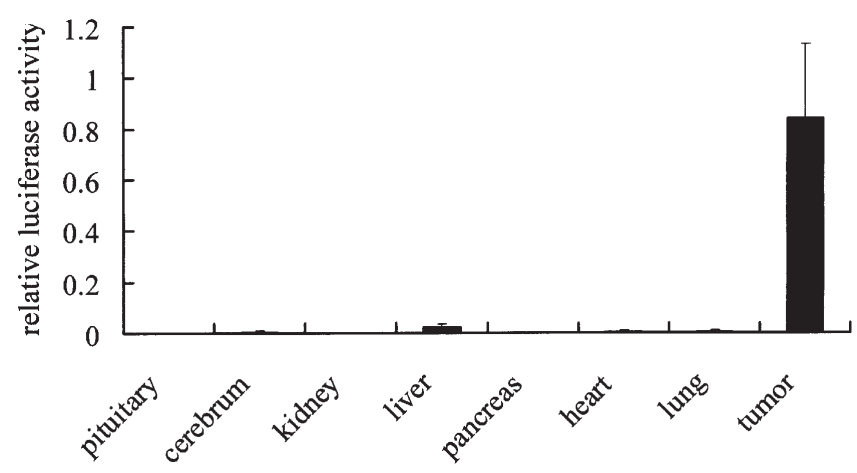

Figure 3. A, EBV-based vector prolonged and enhanced the transgene expression in vivo. The relative luciferase activity in tumors in Wister-Furth rats. Tumor-bearing rats were transfected with pEBGL or pGL. Tumors 5$10 \mathrm{~mm}$ in maximum diameter developed, $200 \mu \mathrm{l}$ of the HVJ-AVE anionic liposome suspension was injected directly into the tumor for three consecutive days. The rats were sacrificed each day and the total homogenate lysates were prepared. The luciferase activities of the homogenates were measured as described above. The ordinate indicates the relative light units of firefly luciferase per rinella luciferase activity. The mean value of quadruplicate plates is indicated. The abscissa represents the days after the gene transfer. When pEBGL was used, the activity increased by day 7 after transfection, and then decreased thereafter. However, the expression level remained constant from day 13 through day 24. The transgene expression ability was 12 times and 84 times higher than that of pGL on day 7 and 21 post transfection, respectively. B, no remarkable transgene expression ability of the EBV-based vector was seen in normal organs/tissues in vivo. The relative luciferase activity in normal organs and tumors of tumor-bearing Wister-Furth rats 7 days after the gene transfer. The plasmid pEBGL-containing HVJ-AVE anionic liposome suspension was directly injected into the tumors in the flank area of rats. The total homogenate lysates of normal organs/tissues or tumors were prepared as described above. The ordinate indicates relative light units at firefly luciferase per rinella luciferase activity. The mean value of quadruplicate plates is indicated. No remarkable luciferase activity was seen in the normal organs or tissue of the tumor-bearing rats compared to that of tumor tissue.

transfection, and thereafter it decreased up until day 12. However, the expression level remained constant after day 13 through day 24. When pGL was used, the luciferase expression was $1 / 12$ and $1 / 84$ times lower than pEBGL on days 7 and 21 , respectively.

To analyze the transgene expression activity of pEBGL in normal organs, plasmid pEBGL and pRLCMV enveloped by HVJ-AVE anionic liposome were injected intratumorally to the tumor-bearing Wister-Furth rats. Either extremely low relative luciferase activity or none at all was found in the samples obtained from normal tissue lysates (Fig. 3B), despite the fact that considerable renilla luciferase activities driven 
A

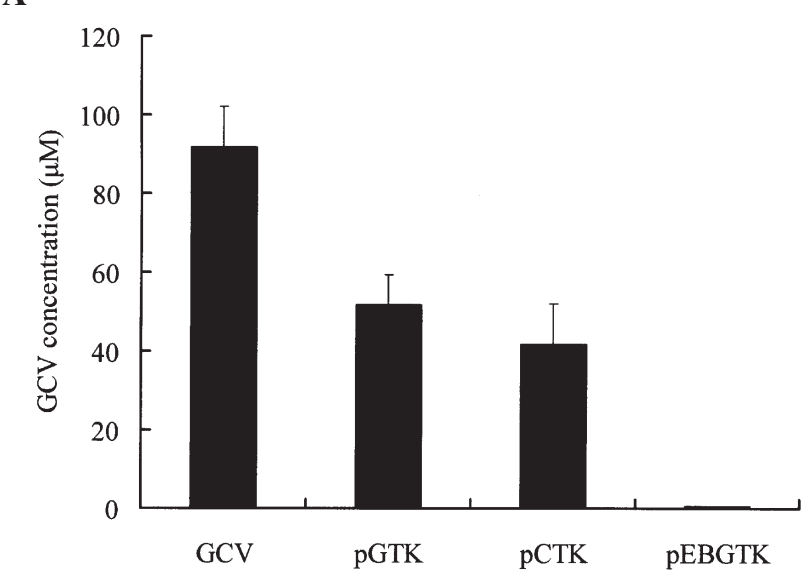

B

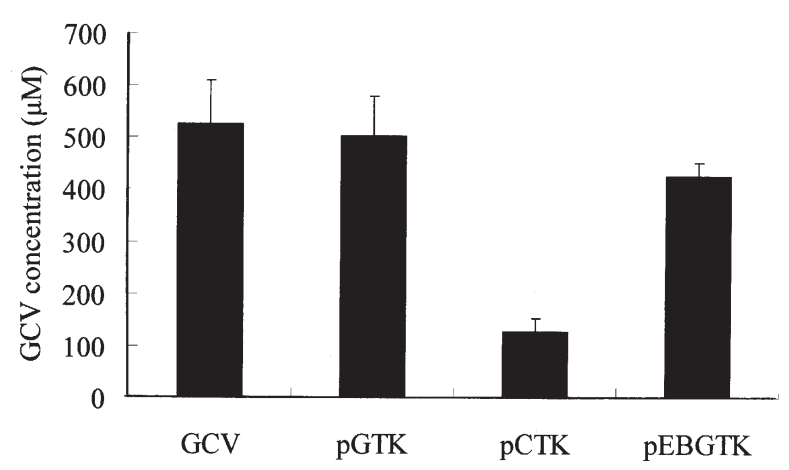

Figure 4. A, a significant enhancement of GCV susceptibility of mGH3 cells was seen for the in vitro gene therapy using the EBV-based vector. On day $0, \mathrm{mGH} 3$ cells were transfected with pGTK or pCTK or pEBGTK, using the HVJ-opDC cationic liposome method. GCV was added to the medium at a final concentration of $0-1000 \mu \mathrm{M}$ daily from day 1 to day 7 . On day 8 , viable cells were counted by means of the trypan blue exclusion method. The median inhibitory concentration $\left(\mathrm{IC}_{50}\right)$, which represents a $50 \%$ growth inhibition relative to the control, was calculated using curving-fitting parameters. The $\mathrm{IC}_{50}$ to $\mathrm{GCV}$ shifted from $91.7 \mu \mathrm{M}$ in control cells (non-transfected cells) to $0.47 \mu \mathrm{M}$ in pEBGTK-transfected cells, thus indicating a 160 -fold reduction by pEBGTK transfection. $B$, no remakable enhancement of the GCV susceptibility was seen in in vitro gene therapy using pGTK or pEBGTK, in the rat glioma C6 cell line. The C6 cells were transfected with pGTK or pCTK or pEBGTK, using the HVJ-opDC cationic liposome method. GCV sensitivity was studied in the same manner as the $\mathrm{mGH} 3$ cell line. The median inhibitory concentration $\left(\mathrm{IC}_{50}\right)$ was calculated. The $\mathrm{IC}_{50}$ to GCV shifted from $526.7 \mu \mathrm{M}$ in the control cells (non-transfected cells) to $127.3 \mu \mathrm{M}$ in pCTK-transfected cells, indicating a 4-fold reduction by pCTK transfection. No significant $\mathrm{IC}_{50}$ reduction was seen in the pGTK- or pEBGTK-treated groups.

by the cytomegalovirus (CMV) promoter were found in all samples (data not shown). These results indicate that the transgene expression ability of pEBGL is tumor specific.

In vitro enhanced $G C V$ sensitivity of $m G H 3$ by transfecting with $p E B G T K$. The plasmids expressing HSV1-TK were transferred to cells using HVJ-opDC cationic liposome to investigate the susceptibility of $\mathrm{mGH} 3$ or $\mathrm{C} 6$ to the toxic gene and GCV. Non-transfected cells and cells transfected with pGTK or pEBGTK were exposed to various concentrations of GCV for 7 days, and cell viability was analyzed by trypan blue exclusion method. Without transfecting any suicide gene expressing plasmids, $50 \mu \mathrm{M}$ of $\mathrm{GCV}$ induced partial cytopathic effects ( $28 \%$ cell killing) on $\mathrm{mGH} 3$ cells.
As shown in Fig. 4A, the 50\% growth inhibitory concentration $\left(\mathrm{IC}_{50}\right)$ of $\mathrm{GCV}$ for non-transfected cells was $91.7 \mu \mathrm{M}$ on average, calculated by curving-fitting parameters. By transfecting pGTK or pCTK using HVJ-opDC liposome, the susceptibility of $\mathrm{mGH} 3$ to GCV was weakly enhanced in comparison with non-transfected cells. The average $\mathrm{IC}_{50}$ of GCV for pGTK- and pCTK-transfected $\mathrm{mGH} 3$ cells was 51.6 and $41.7 \mu \mathrm{M}$, respectively. pEBGTK transfection by HVJopDC liposome significantly increased the GCV sensitivity of the $\mathrm{mGH} 3$, in comparison to the non-transfection group or pGTK- or pCTK-transferred cells. The average $\mathrm{IC}_{50}$ of GCV for the $\mathrm{mGH} 3$ cell line transfected with pEBGTK was $0.47 \mu \mathrm{M}$, thus indicating 90-, 100- and 160-fold reduction in comparison with that of the pCTK-transfected, pGTK-transfected and non-transfected cells, respectively.

For the C6 cell line, no significant enhancement of GCV susceptibility was observed in the cells transferred with pGTK or pEBGTK. A significant increase in the GCV sensitivity was only observed in the cells transfected with pCTK (Fig. 4B). The transfection of plasmids by HVJ-opDC cationic liposomes with no loading of GCV showed no significant cytopathic effect on any of the cell lines.

Significant growth inhibition of established $m G H 3$ tumors in vivo by transferring pEBGTK followed by GCV administration. To evaluate the in vivo antitumor effects on $\mathrm{mGH} 3$ cell tumors by transfection with the plasmid constructs, we injected either BSS or a suspension of the plasmid-enveloping HVJ-AVE liposome into tumors of $\mathrm{mGH} 3$ cells in the subcutis of nude mice, followed by intraperitoneal GCV administration $(50 \mathrm{mg} / \mathrm{kg} \mathrm{B.W}$.), when a maximum tumor diameter of $5 \mathrm{~mm}$ was observed to develop. As shown in Fig. 5, a significant tumor growth delay was only observed in the mice treated with pEBGTK transfection followed by GCV administration ( $\mathrm{P}<0.001$ for any other treatment groups). In this treatment group, one of eight tumors was completely eradicated, and one of eight tumors transiently disappeared. Other tumors showed a transient regression in size until day 6 , and then they grew slowly thereafter. In contrast, the GCV-, pGTK/GCV-, pEBGL/GCV-, and pEBGTK-treated groups failed to show any tumor growth delay effect. Transferring pCTK followed by GCV injection showed a remarkable tumor suppression until day 3, but it failed to show a significant growth delay effect in comparison to the other treatments thereafter $(\mathrm{P}=0.878$ for GCV group). We did not observe any remarkable adverse reactions including death during the treatment course or any loss in body weight.

These results suggest that the Epstein-Barr virus-based expression vector system remarkably enhances the antitumor effect on an in vivo tumor model of rat growth hormone producing pituitary adenocarcinoma.

\section{Discussion}

The HSV1-TK/GCV system is one of the most frequently used systems for suicide gene therapy in experimental cancer gene therapy, and also in clinical trials (42-46). In addition, retrovirus vector is the most often used to transfer this HSV1-TK gene to tumor cells in clinical suicide gene therapy trials for primary glioblastoma multifome (GBM) patients (47-50). The efficacy 


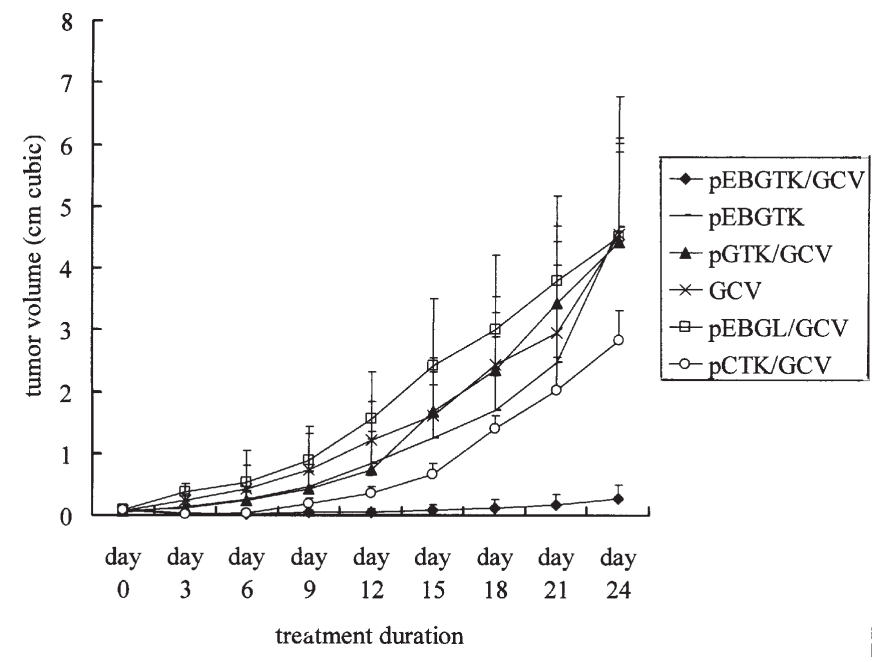

Figure 5. Significant tumor growth delay was seen only in the pEBGTK- and GCV-treated animals. The volume of $\mathrm{mGH} 3$ tumors in nude mice treated with suicide gene therapy. When tumor size reached $5 \mathrm{~mm}$ in maximum diameter after the injection of $\mathrm{mGH} 3$ cells subcutaneously into the flank area of nude mice, mice were divided into 6 treatment groups as follows: group $1(\bullet)$, the tumors were transfected with pEBGTK (day 0-2) followed by daily intraperitoneal GCV injection of $50 \mathrm{mg} / \mathrm{kg}$ body weight (B.W.) from day 2 to day $14(n=8)$; group $2(\Delta)$, the tumors were transfected with pGTK (day 0-2) followed by daily intraperitoneal GCV injection of $50 \mathrm{mg} / \mathrm{kg}$ B.W. from day 2 to day $14(n=8)$; group $3(=)$, the tumors were transfected with pEBGTK (day 0-2) without GCV administration $(n=8)$; group $4(x)$, the tumors were injected with $200 \mu 1$ of BSS (day 0-2) followed by daily intraperitoneal GCV injection of $50 \mathrm{mg} / \mathrm{kg} \mathrm{B}$.W. from day 2 to day 14 $(\mathrm{n}=8)$; group $5(\square)$, the tumors were transfected with pEBGL (day 0-2) followed by daily intraperitoneal GCV injection of $50 \mathrm{mg} / \mathrm{kg} \mathrm{B}$.W. from day 2 to day $14(n=8)$; group $6(0)$, the tumors were transfected with pCTK (day 0-2) followed by daily intraperitoneal GCV injection of $50 \mathrm{mg} / \mathrm{kg} \mathrm{B.W}$. from day 2 to day $14(n=8)$. The tumors were measured every three days by a callipering method, and the tumor volume was calculated using the following formula, (short diameter $)^{2} \times$ (long diameter)/2. The ordinate indicates the relative tumor size, and the abscissa represents duration of treatment. pGTK/GCV, pEBGTK/GCV, pEBGTK, and GCV treatment groups showed no tumor growth delaying effect. Until treatment day 3 , the pCTK/GCV treatment showed a remarkable tumor growth suppression, but it failed to thereafter show a significantly larger growth delay than the other four treatment groups. Only pEBGTK/GCV treatment successfully showed a significant tumor growth delaying effect up until treatment day 24 .

of this paradigm for experimental glioma models has been demonstrated $(51,52)$. However, to date, this gene therapy system has demonstrated only a minimal therapeutic effect on GBMs in clinical use $(50,53)$. This dissociation is caused by the difference in the mitotic activity between an animal glioma model and human GBMs (49). Retroviral vectors can exclusively transfect into dividing cells. The proliferative ability of tumors in nude mice is higher than that of human GBMs (54). The relatively low mitotic activity of the human GBMs causes a low transfection efficiency of the retroviral vectors to tumor cells, thus resulting in the marginal tumor suppression effect in human clinical trials $(48,55)$. Since human pituitary tumors are relatively slow growing compared to GBMs, retrovirus gene transfer system might be not adequate gene therapy for pituitary tumors. The HSV1-TK gene product acts by mono-phosphorylating nucleoside analogues such as gancyclovir, which are then further phosphorylated by cellular kinases to triphosphate metabolites and incorporated into replicating DNA, thus leading to apoptosis $(56,57)$. As a result, the efficiency of the HSV1-TK/GCV system itself also depends on the mitotic ability of the transduced cells, thus leading to a low anti-tumor effect in clinical use $(48,55)$. The relatively long term expression of transgene is therefore considered to be crucial to achieve an adequate antitumor effect when the HSV1-TK/GCV system was used.

For this reason, an Epstein-Barr virus (EBV) based expression vector system was used in this study. This vector harbors the cis-acting oriP (the latent viral DNA replication origin) and the trans-acting EBV nuclear antigen-1 (EBNA-1) sequences, which are required for the EBV latent infection (34). This latent infection is characterized by an autonomous replication and nuclear retention of the EBV genome in the host cells, both of which are one of the mechanisms through which EBV-based vector activates transgene expression $(35,36)$. In addition, another mechanism is the transcriptional activation of EBNA-1 through its binding to oriP (61). Using this EBVbased luciferase construct, pEBGL, reporter gene assay showed a significantly higher luciferase activity than the non-EBVbased counterpart, pGL, and this strong activity was prolonged until day 7 post-transfection in vitro, and day 25 post-transfection in vivo. This strengthened expression ability thus resulted in a remarkable improvement in tumor controllability. The antitumor ability of pEBGTK/GCV in suicide gene therapy was 110 times that observed in vitro, and 17 times that seen in vivo, in comparison to pGTK/GCV, which did not show any tumor growth inhibition in comparison to only GCV treatment. pCTK vector harbors the TK gene driven by a strong promoter, but not long-term expression ability. Consistently with this, in vivo gene therapy, pCTK/GCV treatment showed a significantly stronger tumor suppression than pEBGTK/GCV at day 3 of the treatment, but less antitumor effect than pEBGTK/GCV, thereafter. According to these results, the long and strong transgene expression ability of the vector system is therefore considered to be one of the most important issues for successful tumor control in cancer gene therapy, and the EBV-based expression vector system is thus considered to be suitable for inducing the expression.

Although pituitary tumors are relatively localized as well as slow growing lesions, these tumors locate in pituitary gland containing various hormone producing cells and easily invade the surrounding structures. Partial destruction of tumor cells is of clinical benefit either because of a mass reduction or because the pathological hormone levels can be lowered. They are biologically well-defined tumors, which usually produce excessive amounts of transcription factors or hormones. These highly-specialized tumor cells provide an opportunity for the targeted expression of therapeutic genes to develop using cell type specific promoters. In this study, we used the rat growth hormone promoter $(-320-0)$ as the tissue-specific promoter for treating $\mathrm{GH}$ producing pituitary adenocarcinoma. No significant luciferase activities were shown by an in vivo reporter gene assay for samples from various normal tissues or the organs of rats, transfected with luciferase gene-harboring plasmids using HVJ-AVE liposome via intratumoral injection. We also could not detect any luciferase activities from the normal pituitary glands of these rats, this may be due to the down-regulation of GH secretion from normal somatotroph cells, thus resulting from an excessive amount of $\mathrm{GH}$ from the $\mathrm{mGH} 3$ tumors. For the in vivo gene therapy using this 
promoter, no remarkable toxicity including weight loss was found in combination with the HSV1-TK and GCV therapy (data not shown).

One of the major limitations of this tissue-specific promoter, concerning suicide gene therapy, is the lower and transient expression activity of the promoter than that of universal type promoter (58-60). In this study, pGL showed low luciferase activities during a short period after the transfection in vitro as well as in vivo. In suicide gene therapy, the transfection of pGTK demonstrated a slight improvement of GCV susceptibility in vitro, and no significant delaying effect on tumor growth after the administration of GCV in vivo, in comparison with the control animals treated by GCV only. Using the rat GH promoter (-320-0) alone, the level of expression of the HSV1-TK suicide gene was not sufficient to achieve an adequate therapeutic effect, although this promoter restricted the transgene expression only in the tumor, not in normal tissues/organs. In suicide gene therapy, the transgene expression strength of a promoter is one of the major determinants to achieve an adequate therapeutic effect $(40,41,44)$. Therefore, to obtain measurable anti-tumor abilities in this tissue-specific gene therapy, the expression activities of the promoters need to be strengthened. From this point of view, the EBV-based expression vector system is sufficient to obtain transgene expression even if under the control of tissue-specific promoters.

Fig. 4A showed that the $\mathrm{IC}_{50}$ of pEBGTK is significantly lower than that of pCTK, although the promoter activity itself of pCTK (hCMV promoter) is approximately 49-times higher than that of pEBGTK (rat GH promoter). This significant dissociation is not explained only by the relatively long-term expression ability of an EBV-based vector. Since one of the critical disadvantages of using a non-viral vector is the posttransfection inactivation of vectors, an EBV-based vector system may have compensatory mechanisms against this type of intracellular inactivation (61). Episomal maintenance can allow the vector to avoid cellular inactivation, and this may be an important feature of EBV-based vectors.

This pEBGTK/GCV treatment strategy resulted in no remarkable gene therapy-induced adverse reaction, including weight loss or death either during the treatment or observation period. Using the viral vector, such as adenoviruses, with weak promoters, such as tissue-specific promoters, in suicide gene therapy, a higher amount of the virus would thus be needed to obtain a remarkable therapeutic effect $(24,36,62)$, than the universal promoter used. This leads to an increased risk of liver toxicity (63) as well as chronic cerebral inflammation induced by the viruses $(22,25,26)$. HVJ-liposome has been developed as a fusion liposome vector with inactivated HVJ virus to obtain high transfection efficiency compared with ordinary liposome vectors. Different from viral vectors, HVJliposome does not contain viral DNA at all, and seldom yields immune reaction as well as liposome (40). In this study, by using the EBV-based vector and non-viral HVJ-liposome transfection, the strengthening of the transgene expression in tissue-specific gene therapy was thus able to elicit a beneficial therapeutic outcome, which resulted in improved tumor control with no serious side-effects.

The most important issue of this system concerns its safety in human gene therapy, especially the potential oncogenicity of
EBNA-1 $(30,61)$. Wilson et al reported that B cell lymphoma occurred in EBNA-1 transgenic mice (64). In our vector system, EBNA-1 is driven by the human cytomegalovirus promoter. This promoter is usually inactivated in transfected cells by physiological intracellular mechanisms. The long-term and high-level expression of EBNA-1 is considered to be related to the transforming activity of this gene and, as a result, the transient expression in our system may not result in tumorigenicity. Further investigation to confirm the safety of this vector system is required. However, these results demonstrated the first evidence that a novel type of EBV-based suicide gene therapy can contribute to an effective and selective gene therapy for $\mathrm{GH}$ producing pituitary tumors, which are refractory to conventional therapy.

\section{References}

1. Daniels GH and Martin JB: Neuroendocrine regulation and diseases of the anterior pituitary and hypothalamus. In: Harrison's Principles of Internal Medicine. 13th edition. Isselbacher KJ, Braunwald E, Wilson JD, Martin JB, Fauci AS and Kasper DL (eds). McGraw-Hill, New York, pp1891-1918, 1995.

2. Castro MG: Gene therapy strategies for treatment of pituitary tumours. J Mol Endocrinol 22: 9-18, 1999.

3. Scheithauer BW, Kurtkaya-Yapicier O, Kovacs KT, Young WF Jr and Lloyd RV: Pituitary carcinoma: a clinicopathological review. Neurosurgery 56: 1066-1074, 2005.

4. Kaltsas GA, Nomikos P, Kontogeorgos G, Buchfelder M and Grossman AB: Clinical review: diagnosis and management of pituitary carcinomas. J Clin Endocrinol Metab 90: 3089-3099, 2005.

5. Pernicone PJ, Scheithauer BW, Sebo TJ, Kovacs KT, Horvath E, Young WF Jr, Lloyd RV, Davis DH, Guthrie BL and Schoene WC: Pituitary carcinoma: a clinicopathologic study of 15 cases. Cancer 79: 804-812, 1997.

6. Lopes MB, Scheithauer BW and Schiff D: Pituitary carcinoma: diagnosis and treatment. Endocrine 28: 115-121, 2005.

7. Ragel BT and Couldwell WT: Pituitary carcinoma: a review of the literature. Neurosurg Focus 16: 1-9, 2004.

8. Kovacs K, Scheithauer BW, Horvath E and Lloid RV: The World Health Organization classification of adenohypophysial neoplasms. A proposed five-year scheme. Cancer 78: 502-510, 1996.

9. Lee EJ and Jameson JL: Gene therapy of pituitary diseases. J Endocrinol 185: 353-362, 2005.

10. Seilicovich A, Pisera D, Sciascia SA, Candolfi M, Puntel M, Xiong W, Jaita G and Castro MG: Gene therapy for pituitary tumors. Curr Gene Ther 5: 559-572, 2005.

11. Lee EJ and Jameson JL: Cell-specific Cre-mediated activation of the diphtheria toxin gene in pituitary tumor cells: potential for cytotoxic gene therapy. Hum Gene Ther 13: 533-542, 2002 .

12. Lee EJ, Martinson F, Kotlar T, Thimmapaya B and Jameson JL: Adenovirus-mediated targeted expression of toxic genes to adrenocorticotropin-producing pituitary tumors using the proopiomelanocortin promoter. J Clin Endocrinol Metab 86: 3400-3409, 2001.

13. Lee EJ, Duan WR, Kotlar T and Jameson JL: Restoration of growth hormone-releasing hormone (GHRH) responsiveness in pituitary GH3 cells by adenovirus-directed expression of the human GHRH receptor. Endocrinology 142: 414-420, 2001.

14. Lee EJ, Anderson LM, Thimmapaya B and Jameson JL: Targeted expression of toxic genes directed by pituitary hormone promoters: a potential strategy for adenovirus-mediated gene therapy of pituitary tumors. J Clin Endocrinol Metab 84: 786-794, 1999.

15. Smith-Arica JR, Williams JC, Stone D, Smith J, Lowenstein PR and Castro MG: Switching on and off transgene expression within lactotrophic cells in the anterior pituitary gland in vivo. Endocrinology 142: 2521-2532, 2001.

16. Castro MG, Goya RG, Sosa YE, Rowe J, Larregina A, Morelli A and Lowenstein PR: Expression of transgenes in normal and neoplastic anterior pituitary cells using recombinant adenoviruses: long term expression, cell cycle dependency, and effects on hormone secretion. Endocrinology 138: 2184-2194, 1997. 
17. Southgate TD, Windeatt S, Smith-Arica J, Gerdes CA, Perone MJ, Morris I, Davis JR, Klatzmann D, Lowenstein PR and Castro MG: Transcriptional targeting to anterior pituitary lactotrophic cells using recombinant adenovirus vectors in vitro and in vivo in normal and estrogen/sulpiride-induced hyperplastic anterior pituitaries. Endocrinology 141: 3493-3505, 2000.

18. Windeatt S, Southgate TD, Dewey RA, Bolognani F, Perone MJ, Larregina AT, Maleniak TC, Morris ID, Goya RG, Klatzmann D, Lowenstein PR and Castro MG: Adenovirus-mediated herpes simplex virus type-1 thymidine kinase gene therapy suppresses oestrogen-induced pituitary prolactinomas. J Clin Endocrinol Metab 85: 1296-1305, 2000.

19. Lee EJ, Thimmapaya B and Jameson JL: Stereotactic injection of adenoviral vectors that target gene expression to specific pituitary cell types: implications for gene therapy. Neurosurgery 46: 1461-1468, 2000.

20. Davis JR, McVerry J, Lincoln GA, Windeatt S, Lowenstein PR, Castro MG and McNeilly AS: Cell type-specific adenoviral transgene expression in the intact ovine pituitary gland after stereotaxic delivery: an in vivo system for long-term multiple parameter evaluation of human pituitary gene therapy. Endocrinology 142: 795-801, 2001.

21. Castro MG, Southgate T and Lowenstein PR: Molecular therapy in a model neuroendocrine disease: developing clinical gene therapy for pituitary tumours. Trends Endocrinol Metab 12: 58-64, 2001.

22. Dewey RA, Morrissey G, Cowsill CM, Stone D, Bolognani F, Dodd NJF, Southgate TD, Klatzmann D, Lassmann H, Castro MG and Lowenstein PR: Chronic brain inflammation and persistent herpes simplex virus 1 thymidine kinase expression in survivors of syngeneic glioma treated by adenovirus-mediated gene therapy: implication for clinical trials. Nat Med 5: 1256-1263, 1999.

23. Kielian T and Hickey W: Inflammatory thoughts about glioma gene therapy. Nat Med 5: 1237-1238, 1999.

24. Thomas CE, Schneider G, Kochanek S, Castro MG and Lowenstein PR: Peripheral infection with adenovirus causes unexpected long-term brain inflammation in animals injected intracranially with first generation, but not with high-capacity adenovirus vectors: towards realistic long-term neurological gene therapy for chronic diseases. Proc Natl Acad Sci USA 97: 7482-7487, 2000.

25. Smith JA, Raper SE, Wheeldon EB, Hackney D, Judy K, Wilson JM and Eck SL: Intracranial administration of adenovirus expressing HSV-TK in combination with ganciclovir produces a dose-dependent, self-limiting inflammatory response. Hum Gene Ther 8: 943-954, 1997.

26. Goodman JC, Trask TW, Chen SH, Woo SLC, Grossman RG, Carey KD, Hubbard GB, Carrier DA, Rajagopalan S, Aguilar-Cordova E and Shine HD: Adenoviral-mediated thymidine kinase gene transfer into the primate brain followed by systemic ganciclovir: pathologic, radiologic, and molecular studies. Hum Gene Ther 7: 1241-1250, 1996

27. Rogulski KR, Wing MS, Paielli DL, Gilbert JD, Kim JH and Freytag SO: Double suicide gene therapy augments the antitumor activity of a replication-competent lytic adenovirus through enhanced cytotoxicity and radiosensitization. Hum Gene Ther 11: 67-76, 2000.

28. Davis JR, McMahon RF, Lowenstein PR, Castro MG, Lincoln GA and McNeilly AS: Adenovirus-mediated gene transfer in the ovine pituitary gland is associated with hypophysitis. J Endocrinol 173: 265-271, 2002.

29. Thapar K, Yamada Y, Scheithauer B, Kovacs K, Yamada S and Stefaneanu L: Assessment of mitotic activity in pituitary adenomas and carcinomas. Endocr Pathol 7: 215-221, 1996.

30. Conese M, Auriche C and Ascenzioni F: Gene therapy progress and prospects: episomally maintained self-replicating systems. Gene Ther 11: 1735-1741, 2004.

31. Kodama K, Katayama Y, Shoji Y and Nakashima H: The features and shortcomings for gene delivery of current non-viral carriers. Curr Med Chem 13: 2155-2161, 2006.

32. Thomas L: A non-viral vector for in vivo gene delivery. Lancet Neurol 4: 602, 2005.

33. Miller AD: The problem with cationic liposome/micelle-based non-viral vector systems for gene therapy. Curr Med Chem 10: 1195-1211, 2003

34. Leight ER and Sugden B: EBNA-1: a protein pivotal to latent infection by Epstein-Barr virus. Rev Med Virol 10: 83-100, 2000.

35. Mizuguchi H, Hosono T and Hayakawa T: Long-term replication of Epstein-Barr virus-derived episomal vectors in the rodent cells. FEBS Lett 472: 173-178, 2000.
36. Saeki Y, Wataya-Kaneda M, Tanaka K and Kaneda Y: Sustained transgene expression in vitro and in vivo using an Epstein-Barr virus replicon vector system combined with HVJ liposomes. Gene Ther 5: 1031-1037, 1998.

37. Akino K, Ohtsuru A, Yano H, Ozeki S, Namba H, Nakashima M, Ito $\mathrm{M}$, Matsumoto $\mathrm{T}$ and Yamashita $\mathrm{S}$ : Antisense inhibition of parathyroid hormone-related peptide gene expression reduces malignant pituitary tumor progression and metastases in the rat. Cancer Res 56: 77-86, 1996.

38. Kaneda Y, Saeki Y, Nakabayashi M, Zhou WZ, WatayaKaneda M and Morishita R: Enhancement of transgene expression by cotransfection of oriP plasmid with EBNA-1 expression vector. Hum Gene Ther 11: 471-479, 2000.

39. Saeki Y, Wataya-Kaneda M, Tanaka K and Kaneda Y: Sustained transgene expression in vitro and in vivo using an Epstein-Barr virus replicon vector system combined with HVJ liposomes. Gene Ther 5: 1031-1037, 1998 .

40. Kaneda Y: Development of a novel fusogenic viral liposome system (HVJ-liposomes) and its applications to the treatment of acquired diseases. Mol Membr Biol 16: 119-122, 1999.

41. Kaneda Y, Saeki and Morishita R: Gene therapy using HVJliposomes: the best of both worlds? Mol Med Today 5: 298-303, 1999.

42. Colombo F, Barzon L, Franchin E, Pacenti M, Pinna V, Danieli D, Zanusso $\mathrm{M}$ and Palu G: Combined HSV-TK/IL-2 gene therapy in patients with recurrent glioblastoma multiforme: biological and clinical results. Cancer Gene Ther 12: 835-848, 2005.

43. Moriuchi S, Glorioso JC, Maruno M, Izumoto S, Wolfe D, Huang S, Cohen JB and Yoshimine T: Combination gene therapy for glioblastoma involving herpes simplex virus vectormediated codelivery of mutant IkappaBalpha and HSV thymidine kinase. Cancer Gene Ther 12: 487-496, 2005.

44. Ketola A, Maatta AM, Pasanen T, Tulimaki K and Wahlfors J: Osteosarcoma and chondrosarcoma as targets for virus vectors and herpes simplex virus thymidine kinase/ganciclovir gene therapy. Int J Mol Med 13: 705-710, 2004.

45. Ayala G, Satoh T, Li R, Shalev M, Gdor Y, Aguilar-Cordova E, Frolov A, Wheeler TM, Miles BJ, Rauen K, Teh BS, Butler EB, Thompson TC and Kadmon D: Biological response determinants in HSV-tk + ganciclovir gene therapy for prostate cancer. Mol Ther 13: 716-728, 2006.

46. Pulkkanen KJ and Yla-Herttuala S: Gene therapy for malignant glioma: current clinical status. Mol Ther 12: 585-598, 2005.

47. Aghi M and Chiocca EA: Gene therapy for glioblastoma. Neurosurg Focus 20: E18, 2006.

48. King GD, Curtin JF, Candolfi M, Kroeger K, Lowenstein PR and Castro MG: Gene therapy and targeted toxins for glioma. Curr Gene Ther 5: 535-557, 2005.

49. Rainov NG, Kramm CM, Banning U, Riemann D, Holzhausen H-J, Heidecke V, Burger KJ, Burkert W and Korholz D: Immune response induced by retrovirus-mediated HSV-tk/GCV pharmacogene therapy in patients with glioblastoma multiforme. Gene Ther 7: 1853-1858, 2000.

50. Rainov NG: A phase III clinical evaluation of herpes simplex virus type 1 thymidine kinase and ganciclovir gene therapy as an adjuvant to surgical resection and radiation in adults with previously untreated glioblastoma multiforme. Hum Gene Ther 11: 2389-2401, 2000

51. Martinet O, Schreyer N, Reis ED and Joseph JM: Encapsulation of packaging cell line results in successful retroviral-mediated transfer of a suicide gene in vivo in an experimental model of glioblastoma. Eur J Surg Oncol 29: 351-357, 2003.

52. Takamiya Y, Short MP, Ezzeddine ZD, Moolten FL, Breakefield XO and Martuza RL: Gene therapy of malignant brain tumors: a rat glioma line bearing the herpes simplex virus type 1-thymidine kinase gene and wild-type retrovirus kills other tumor cells. J Neurosci Res 33: 493-503, 1992.

53. Prados MD, McDermott M, Chang SM, Wilson CB, Fick J, Culver KW, van Gilder J, Keles GE, Spence A and Berger M: Treatment of progressive or recurrent glioblastoma multiforme in adults with herpes simplex virus thymidine kinase gene vectorproducer cells followed by intravenous ganciclovir administration: a phase I/II multi-institutional trial. J Neurooncol 65: 269-278, 2003.

54. Tamiya T, Wei MX, Chase M, Ono Y, Lee F, Breakefield XO and Chiocca EA: Transgene inheritance and retroviral infection contribute to the efficiency of gene expression in solid tumors inoculated with retroviral vector producer cells. Gene Ther 2: $531-538,1995$. 
55. Harsh GR, Deisboeck TS, Louis DN, Hilton J, Colvin M, Silver JS, Qureshi NH, Kracher J, Finkelstein D, Chiocca EA and Hochberg FH: Thymidine kinase activation of ganciclovir in recurrent malignant gliomas: a gene-marking and neuropathological study. J Neurosurg 92: 804-811, 2000.

56. Freeman SM, Abboud CN, Whartenby KA, Packman $\mathrm{CH}$, Koeplin DS, Moolten FL and Abraham GN: The 'bystander effect': tumor regression when a fraction of the tumor mass is genetically modified. Cancer Res 53: 5274-5283, 1993.

57. Wintersberger E, Rotheneder H, Grabner M, Beck G and Seiser C: Regulation of thymidine kinase during growth, cell cycle and differentiation. Adv Enzyme Regul 32: 241-254, 1992.

58. Weeratna RD, Wu T, Efler SM, Zhang L and Davis HL: Designing gene therapy vectors: avoiding immune responses by using tissue-specific promoters. Gene Ther 8: 1872-1878, 2001.

59. Qiao J, Doubrovin M, Sauter BV, Huang Y, Guo ZS, Balatoni J, Akhurst T, Blasberg RG, Tjuvajev JG, Chen SH and Woo SL: Tumor-specific transcriptional targeting of suicide gene therapy. Gene Ther 9: 168-175, 2002.
60. Fukazawa T, Maeda Y, Sladek FM and Owen-Schaub LB: Development of a cancer-targeted tissue-specific promoter system. Cancer Res 64: 363-369, 2004.

61. Kaneda Y, Saeki Y, Nakabayashi M, Zhou WZ, Kaneda MW and Morishita R: Enhancement of transgene expression by cotransfection of oriP plasmid with EBNA-1 expression vector. Hum Gene Ther 11: 471-479, 2000.

62. Addison CL, Hitt M, Kunsken D and Graham FL: Comparison of human versus murine cytomegalovirus immediate early gene promoters for transgene expression by adenoviral vectors. J Gen Virol 78: 1653-1661, 1997.

63. Brand K, Arnold W, Bartels T, Lieder A, Kay MA, Strauss M and Dorken B: Liver-associated toxicity of the HSV-tk/GCV approach and adenoviral vectors. Cancer Gene Ther 4: 9-16, 1997.

64. Wilson JB, Bell JL and Levine AL: Expression of Epstein-Barr virus nuclear antigen-1 induces $B$ cell neoplasia in transgenic mice. EMBO J 15: 3117-3126, 1996. 